\title{
NOTAS SOBRE JOAQUÍN RODRIGO
}

Walter Hernández Madriz

La intención de estas notas acerca de Joaquín Rodrigo -y ojalá que pudiéramos lograrla- es la de familiarizarse con la figura del compositor más laureado de la historia musical española; excepcional en el siglo XX en el mundo, no solo por lo extensivo de su producción sino por su excelsa calidad.

Imagino el siglo veinte como un gran instrumento musical: Joaquín Rodrigo es la cuerda intensa y prodigiosa que lo atraviesa desde el puente, 1901, hasta la última clavija, 1999. Tuvimos, los habitantes de este planeta, la suerte de que este gran hombre lo cubriera por entero.

En 1901 nace, en Sagundo, ciudad del Levante español, en Valencia, frente a su muy querido Mediterráneo. El mar, el campo y las lecturas fueron, muchas veces, sus musas. La historia de Sagundo nos habla de la entereza y valentía de las raíces de Joaquín Rodrigo: en el 219 a.C., esta ciudad fue sitiada por el gran general Aníbal, el cartaginés, prefiriendo 
sus habitantes morir antes que entregarla. Joaquín Rodrigo se entregó, vivió y murió por, con y para la música.

Nació un 22 de noviembre, muy precisamente el día de Santa Cecilia, patrona de los músicos -nombre vislumbrado para su hija amada-. Penosamente, y por carencia de sueros adecuados, la difteria lo dejaría ciego a sus escasos tres años de edad. Sin embargo, él siempre afirmaría que, quizás, de no haber sido por ese hecho, no hubiese llegado a ser músico. Hubiera deseado ser musicólogo, y manifestaba que su afición absoluta había sido la literatura, la cual no había "cultivado jamás".

En 1923 escribe sus primeras composiciones; tal "La enamorada junto al surtidor" para violín y piano. Al año siguiente, su primer ensayo sinfónico es lanzado por la orquesta de Valencia, dirigida por José Ma. Izquierdo. En 1925 , escribe una obra que tuvo gran relevancia para la vida del compositor y para la que, ocho años después, sería su esposa: "Cinco piezas infantiles".

Dos años más tarde, en el 27, estudia composición en la Escuela Normal de Música de París. Durante los seis años que pasa en esta ciudad, entabla amistad con Ravel, al que describía como pequeño, delgado e irónico. Rodrigo iría al estreno de "Bolero" con su esposa; y confesaba que el concierto no gustó puesto que hubo silbidos.

Conoce a Milhaud, a Stravinsky y a Manuel de Falla. De este último don Joaquín siempre agradecería sus sabios consejos que fueron decisivos en su carrera. Por cierto, muchos años después, habría de crear la Cátedra Manuel de Falla en la Universidad Complutense (1974).

Su matrimonio se llevaría a cabo en 1933 con una mujer extraordinaria: Victoria Kahmi. En Barcelona hace amistad con Miliet, Samper, Lamotte y Salvat. En Madrid lo veían como músico catalán y en París, fue corresponsal de la revista musical catalana. Al casarse, Victoria Kahmi lleva 
consigo un piano Pleyel, pero al regresar a París, tuvieron que venderlo. No fue sino hasta 1959 en que adquirieron un piano de cola marca Bechstein, su sueño de niño.

Para 1935, ya daba conferencias en la Sorbona, pero, tres años después, aún sobrevivía musicalizando anuncios y haciendo arreglos para orquesta de café. Más tarde, estudia musicología en Alemania. Viaja a Austria y, en París, les toma la guerra. En Alemania y Austria, pensaba, "la música era un artículo de primera necesidad". Fue esta, sin lugar a dudas, la época de mayores vicisitudes, de penurias y necesidades insatisfechas que padeció al matrimonio Rodrigo, con frecuencia adioses y despedidas que, finalmente, y con las agallas de ambos, lograron superar.

Estaba muy cerca ya la fecha cumbre de su carrera, el año 1940, cuando, en Barcelona, su patria chica, se estrenara el "Concierto de Aranjuez", para guitarra y orquesta. Increíblemente, no fue Andrés Segovia su intérprete, como se hubiese esperado; lo hizo un guitarrista excelente aunque no de la estatura musical de aquel, Sáinz de la Masa, buen amigo, quien tuvo que esforzarse mucho intentando nuevas técnicas para digerir aquello que tenía enfrente. $Y$ el concierto fue un éxito.

Como crítico, comentarista, pianista y conferencista exquisito, Joaquín Rodrigo viajó por España, Europa y Japón fue profesor invitado de la Universidad Río Piedras en Puerto Rico. Trabajaba no solo sus partituras sino sobre textos, reflexiones, conferencias, correspondencia, estudios y escritos diversos.

Como ciudadano, despreciaba la política y los juegos de azar, no la democracia. Fumaba pipa y, jocosamente, afirmaba comerse las uñas mientras componía, prefiriendo hacerlo sobre el mismo piano y ojalá en otoño. Le embargaba un gran optimismo, recitado por su sonrisa permanente, envuelto en una densa sinceridad. Poseía una personalidad 
caudalosa y consideraba no haber sido un niño prodigio, como sí fue así considerada la niña Victoria Kahmi por la gente de su pueblo en Pasa Mablé en Turquía, después de haber interpretado una canción al piano a los tres años y medio de edad.

Nuestro compositor era un modelo de actividad, inquieto, incansable en la labor y muy eficaz. Su música penetra la profundidad del sentimiento humano con la mayor de las cualidades de un genio: la sencillez, la misma que destila un gran respeto por el ser humano, por la vida, y que se yergue sobre el pilar de lo que él más deseaba: el amor de los suyos y la paz duradera.

Rodrigo llega a la propia Valencia a la edad de 4 años. Su Valencia paradójicamente, la ciudad con su "ritmo pausado pero con gran capacidad para inflamarse", donde estudió en el colegio para invidentes desde los 7 hasta los 17 años. Descendiente de labradores, su padre fue un terrateniente y su madre una aldeana con gran sensibilidad por la música. Ella era enérgica, activa y ordenada. Siendo el penúltimo de diez hermanos, menor de cuatro varones, se fue formando en la música escuchando el gramógrafo y la pianola, "El ave de Otelo" con Carusso, por ejemplo. El primer concierto que escuchó fue para clavecín, a Wanda Handowska.

Habiendo cumplido los veinte años, compuso su primera suite para piano y según sus palabras; "...en ella estaban plasmadas sus inquietudes e intenciones" musicales; todo lo que iba a seguir era "madurar".

Su padre pretendía que su hijo no emprendiera, por su condición, ningún proyecto atrevido; sin embargo, con sus propios ahorros Joaquín partió para París a los 25 años, y allí habría de encontrar el complemento de su vida. En el primer año vendió todo lo que había escrito. Su padre mantuvo su estadía allá mientras perdía su fortuna. Igual suerte correría la familia Kahmi. 
De la música española decía que España se quedaría sin músicos, que se "aplebeyaba" la canción andaluza, presintiendo la decadencia del canto flamenco. Él mismo decía que Adolfo Salazar había ejercido una gran influencia sobre su generación. Por otra parte, la obra que le había impresionado (entre el 27 y el 33) fue "Arienne et Barbe-Bleue" de Paul Dukas, su gran maestro; este, además de detestar a Brahms y a Prokofiev, le enseñó a ser ecléctico y a amar la música. Fue devoto de Stravinsky (menos de su "Edipo Rey"), de Stroenberg y de Bartók. Para él, la revelación y gran figura de su tiempo era Handemith.

Es a Manuel de Falla a quien debe su debut parisino, interpretando "Zarabanda Lejana" y el "Preludio al gallo mañanero", obra por la cual Virginia Kahmi quiso conocerlo. De Falla se le antoja una personalidad misteriosa, compleja; lo sentía sobrio, sutil, muy callado. Falla tuvo influencia sobre él, pero no el andaluz -decía- sino el castellano de "El Retablo de Maese Pedro".

Enamorado de la música (la otra mitad de su vida eran la historia, la filosofía, la literatura y la poesía), el maestro Rodrigo creía que los compositores comprendían una especie por extinguirse: ellos eran inseguros y se iban de la mano tras varias corrientes. El ritmo había sido el elemento musical más descuidado por parte de ellos; sin embargo, para él, la melodía tenía prioridad. Lamentaba que Albéniz (cuya suite "Iberia" le significaba "la espina dorsal de nuestra música") y Granados murieran muy jóvenes y que de Falla escribiera hasta los cuarenta y cinco. Pensó de ellos que no superaron la etapa folclórica. A propósito de la composición, Rodrigo no asumía la inspiración por sí misma: dictaba que si uno se ponía a esperarla, podría hacerlo durante toda la vida; además, puntualizaba que Dios está en la naturaleza y que a Él sí lo intuía; más bien, y muy conciente de que el músico debía ser remunerado como se 
debe, añadía que la inspiración venía después del encargo, y que precisamente en la composición reside lo más placentero para el artista.

Algunos de estos encargos fueron:

- "Concierto en modo galante", para el violoncellista Gaspar Cassadó, 1949,

- "Concierto Serenata", para el arpista Nicanor Zabaleta, 1952,

- "Fantasía para un gentilhombre", para Andrés Segovia, 1954, basado en la música de Gaspar Sánz, español del S. XVI,

- "Concierto Andaluz" para el cuarteto Romero, 1967 ,

- "Concierto Pastoral" para el flautista John Gallway, 1978, y

- "El Concierto para un divertimento" para el violoncellista Julian Lloyd Weber.

Al principio -según cuenta Montsalvage-, Rodrigo tuvo como ídolo a Chopin, en su niñez, en su adolescencia, prefirió a Debussy y a Stravinsky. No soportaba a Beethoven y no deseaba regresar a Bach; pero, con el tiempo, sus preferencias cambiaron: fueron sus ídolos de madurez y llegó a afirmar que si tuviese que salvar algunas obras de las llamas de un incendio, serían:

\footnotetext{
- "La Pasión según San Mateo" de Bach, "El Retablo" de Falla, "Leonora" de Beethoven, "El Mar" de Debussy, y el preludio "Le Sacre" de Stravinsky.
} 
Personalmente, él salvaría "El Cántico a la Esposa", obra suya, dedicada a Victoria Kahmi, por supuesto, basada en versos de San Juan de la Cruz, porque es -decía- una obra despojada de lo accesorio que conlleva toda creación artística. Curiosamente, no le hubiera interesado rescatar a Wagner.

"Bagatela" fue la obra que menos le costó escribir; la más popular, "La Pastoral"; de las más difíciles en tiempo, "El gallo mañanero"; "El Concierto Heroico", la obra más larga compuesta en el menor tiempo; y la que más disgustos le propinó fue "Cinco Piezas Infantiles", pero que le propinó una gran recompensa porque, a través de ella, conocería a su esposa, su compañera infaltable y su mejor consejera, discípula, también, de Paul Dukas. A Dukas, Rodrigo lo veía como un hombre íntegro y bondadoso, con "agudo sentido autocrítico", quien, en un acto solo por él sabido, antes de morir, quemó toda su producción inédita.

Por aquellos años, Rodrigo afirmaba que la gente era aficionada al disco, no a los conciertos. Indicaba que el disco era un "verdadero libro musical" fabricado, no espontáneo, de modo que nunca superaría a la audición directa que es viva, real. De la música popular opinaba que la canción era una manifestación del espíritu de los pueblos, y que la radio tenía la potestad de transformar una canción en una obsesión.

De la música dodecafónica pensaba que era un "istmo" de la composición, que "llegué tarde pero me permito con ella algún coqueteo". Y: "la disonancia no existe (...) porque se ha integrado por completo a la consonancia".

Lo esencial, para él, no era entender la música sino sentirla, y deseaba que la buena estuviera al alcance de todos los bolsillos, tratando de no allegarse a la música fácil. Aseguraba que la calificación de un género no debía entrañar la idea de bondad o maldad: una zarzuela, por ejemplo, no era buena o mala sino acertada o desacertada. 
Cuando le preguntaban sobre su "Concierto de Aranjuez", expresaba que "seguiría gustando dentro de un siglo, en el caso de que el hombre conserve dentro de un siglo narices y orejas, que lo dudo...". Le encantaba el flamenco, el cante jondo, entre más viejo mejor, y refería que para aprenderlo era menester descorchar muchas botellas de jerez. Y del "Concierto": "Ahí hay flamenco, pero, ¡ojo!, no he quitado ni una nota a nadie. Todo es mío". Observaba que el "Aranjuez", fluidamente compuesto, era la "feliz unión de lo clásico con lo castizo y de lo aristocrático con lo popular".

Por otro lado, con respecto de su visión, reconocía: "No soy total y absolutamente ciego, percibo la proximidad de los objetos, pero sin contornos (...), advierto las masas cercanas y las conozco por deducción". Como apuntó Víctor Ruiz: Rodrigo es "sensible a la luz y a los bultos, no a las formas". En una de las múltiples entrevistas que ofreció en vida (compiladas por Antonio Iglesias en su excelente libro Escritos de Joaquín Rodrigo), el compositor decía, del mundo de la ceguera, que "no se tienen deseos de salir de ese mundo, aunque es delicioso contemplar un paisaje, un buen cuadro".

Fue jefe de propaganda de la ONCE, Organización Nacional de Ciegos. Para esos últimos solicitaba un trato delicado, de respeto y cariño. Alguna vez dijo que "antes sentía los colores", después no. "fuera de la cara de mi hija, lo único que atrae mi afán curioso es el Arte".

Tuvo un piano Gómez, y -lo que es realmente sorprendente- notación musical ordinaria, y aquí es donde aparecía el talento de Victoria Kahmi: ella las revisaba e interpretada y, junto con su esposo, las corregían. Ella exponía que "por escribir en Braille, la intimidad del artista (su esposo) es doble". 
Cuando leí De la mano de Joaquín Rodrigo -Historia de nuestra vida. Comprendí por qué ella encarnaba, amén de mucho más, los ojos de su esposo: tenía una memoria fabulosa y el estilo con que escribe la biografía es sincero, claro y con un gran poder descriptivo, sin perder del más menudo de los hilos.

En una ocasión, el compositor le pidió a un entrevistador: "Ponga allí que la mitad de Joaquín Rodrigo es su esposa". Ella, que había nacido en Turquía, Constantinopla, de los aires bizantinos frente al Bósforo, de padres extremadamente ricos como comerciantes, cuya niñez fue realmente un cuento de "Las mil y una noches", con palacios y sultanes, rigor religioso y peregrinaciones a la Meca, llega un día hasta el hombre levantino del otro lado del mundo, unidos por el contundente "signo de la música". Una música, como estimara Pedro Rocamora, "donde no hay dramatismo ni amargura. Sino un mensaje puro, hondo, lírico y delicado" que no "busca nuestra angustia ni nuestra crispación", porque como reza el epígrafe en la primera parte del libro de V. Karhmi, citando a Schumann: "Enviar luz a la profundidad del corazón humano es la profesión del artista". Para Joaquín Rodrigo, la música conlleva una función educativa que hace que las personas se sensibilicen más social y vitalmente. Sostenía que la música poseía valores mágicos y milagrosos y que, además, resultaba "una positiva influencia moral".

El maestro, a pesar de su declarada timidez, pudo ser tremendamente romántico y exponer que a una mujer puede llevarnos "su voz, su perfume, su pensamiento".

Le encantaban las tertulias de café -café con poco azúcar-, una en la tarde y otra durante la noche, y sus compañeros, por lo general, eran poetas: Gerardo Diego, Luis Rosales, Cossío, Vivancio, Eugenio D'ors y Machado. Se 
sentía perteneciente a la generación de Gerardo Diego, Rafael Alberti y Federico García Lorca. Llegó a pronunciar que "...la música es la máxima poesía de que dispone el hombre". De hecho, también, trabajó, musicalmente, aparte de los de San Juan de la Cruz, versos de Lope de Vega y de Miguel de Unamuno al que admiraba profundamente.

Pensaba que en el ser humano había dos vidas: una interna y personal y otra mundana: gozaba con ambas. Deseaba que el día se extendiera a treinta horas y prefería que sus obras estuvieran en borrador antes de llegar a terminarlas, porque la expectativa artística hace de la vida del artista una situación especialmente deliciosa aunque conlleve tensión y pesar: "Me parece que siempre estoy empezando".

Para él, el hombre cantó mucho antes de hablar, porque la música le es inherente al ser humano, reside en lo más hondo y su acto es tan natural como llorar o reír. Señalaba que, hasta el $\mathrm{S}$. XV, la música estuvo en la garganta del hombre, en el S. XVII pasa a sus manos y cuando surge el ballet desciende hasta sus pies. Con el celuloide y la música electrónica, la música "empieza a vivir sin el hombre".

Escribió música para el cine, la cual -según su parecer- debía cumplir la función de subrayar las voces, los gestos, el sentimiento, el pensamiento de los intérpretes; expresar lo que la palabra ni el paisaje podían decir de una manera completa. Explicaba, también, que el arte no progresa, se transforma.

Defensor de los músicos como artífices del arte, decía que era lastimoso que los honores no estuvieran en relación con los honorarios; que los mejores elogios que recibió fueron para el estreno de "Fantasía para un gentilhombre" en el Monumental de Madrid, ciudad a la que llamaba el "feudo donde trabajo, lucho y combato". Cuando no componía, 
comía y dormía bien: eran sus "períodos de encantamiento"; en cambio, en tanto componía, la pasaba muy mal.

Reconocía en los intérpretes una gran importancia porque -aseveraba- son los intermediarios entre el público y el compositor; traen desde él su mensaje.

Un merecidísimo reconocimiento para el compositor, entre muchos otros, se suscitaría en el año 1991: fue nombrado Marqués de los Jardines de Aranjuez.

Ocho años más tarde, en Madrid, Joaquín Rodrigo, el 6 de julio de 1999, nos dejó sin su genio. Hacía dos años atrás, exactamente, lo había hecho su Victoria Kahmi.

Para celebrar el centenario del nacimiento del maestro en Costa Rica, el 4 de setiembre del 2001 tuvimos la presencia concertista del guitarrista Manuel Barrueco, reconocido como el más fidedigno intérprete del Concierto de Aranjuez, gracias al esfuerzo del guitarrista nacional Pablo Ortiz y con el beneplácito de la hija del compositor, Cecilia Rodrigo.

Alguna vez el maestro manifestó que, de escoger para sí un epitafio, sería: "Su vaso fue pequeño, pero bebió en su vaso".

En los días de ese homenaje póstumo, el maestro nos permitió compartir un sorbo delicioso de ese vaso suyo, musicalmente inmortal.

Agosto, 2001 